\title{
Bioclimatic Design Strategies Recommendations for Thermal Comfort Using Mahoney Tables
}

\author{
Dr. Ghada Elshafei \\ Assistant Professor, Department of Architectural Engineering, Faculty of Engineering, Minia \\ University \\ ghada.elshafei@mu.edu.eg
}

\begin{abstract}
Thermal comfort is the result of a balanced of building frameworks adjusted to both the area of the structure just as the kind of air move performed inside the structure or the room of the structure. The aim of this research is to represent the Minia city as a case study based on the Mahoney tables method to validate the best design strategy in the hot desert bioclimatic region. Mahoney tables are a collection of referenced tables utilized in construction as a climateappropriate design manager coupled with the meteorological data to include the right design recommendations. So, the Mahoney tables can assess the climate to be more accurately reflect the environmental conditions in the summer. Also, it can beware of the passive heating technique as natural ventilation used in the construction of energy-efficient buildings. The research proceeds with a set of conclusions and recommendations that be gotten from Mahoney tables climatic characteristics, then the design strategies were recommended. These recommendations can help architects bring forward a set of bioclimatic design strategies for buildings in Minia's environment to conduct thermal comfort with the help of the climate consultant tool.
\end{abstract}

KEYWORDS: Bioclimatic Design; Climate Consultant; Hot-Desert climate; Mahoney Tables; Thermal comfort.

$$
\text { توصيات استراتيجيات للراحة الحرارية باستخدام جداول ماهوني }
$$

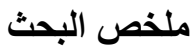

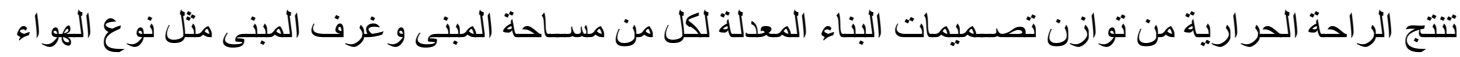

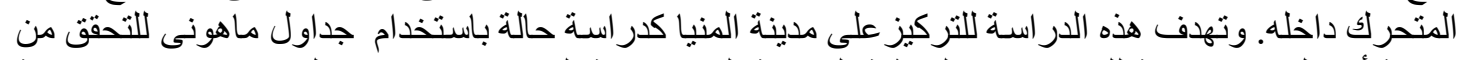

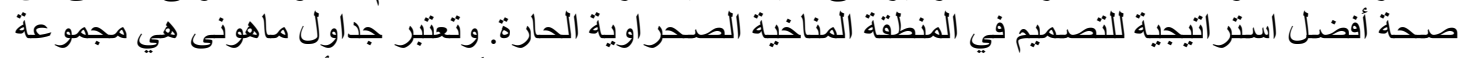

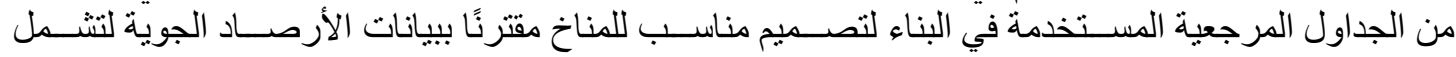

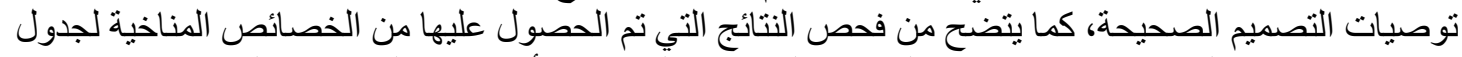

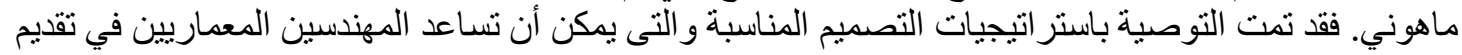

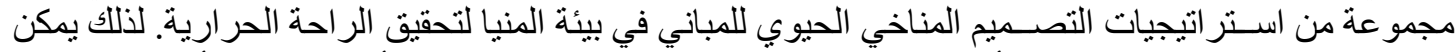

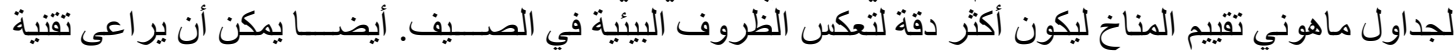
التهوية الطبيعية المستخدمة في تثيبيد المباني الموفرة للطناقة.

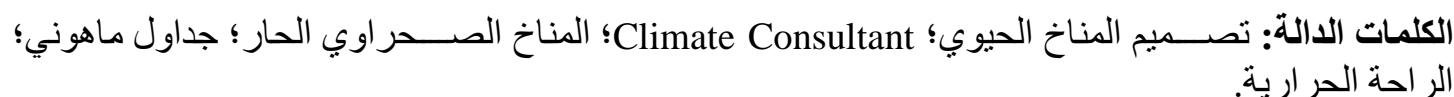

\section{INTRODUCTION}

The Architectural Association's Department of Architecture and Tropical Studies (AADATS) in London developed a climate-conscious building architecture approach [ 
Sayigh, et al. 1998]. The approach that is suggested is built on three strategy phases, the strategy stage of the concept, the planning stage of the proposal, and the design stage of the components [Givoni, 1992]. They developed the Mahoney tables, which work on thermal comfort utilizing Standard Effective Temperature (SET) for systematic study during the three phases. The tables are used to evaluate the features of the environment, since that architecture indicators are attained. Then an initial image of the design, shape, orientation, and construction of the environment can be gained from such indicators. However, these indicators differ from climatic region to another regarding its bioclimatic characteristics. On the other hand, this study focuses on one of the cities in Egypt, which has a hot- desert climate.

Egypt has a set of climate zones that range from very hot to cold [Mahmoud, 2011], with high solar radiation levels [Megahed, 2020]. The (EREC) Egyptian Residential Energy Code classified the Egyptian climate into eight different climatic zones as shown in Fig. 1 [Egyptian Code, 2008]. Also, the figure shows the classification of the Egyptian climatic zones and the location of the chosen case study Minia city. As the adaptive comfort principle, and some researcher's details, the individual living in hot environments will acclimatize with the higher temperature [Humphreys, 1996, 2013, Givoni, 1998]. The zone of the thermal comfort that is between $20^{\circ} \mathrm{C}$ to $29^{\circ} \mathrm{C}$ utilized in this study is an adjusted variation of the original one that laid between $22.2^{\circ} \mathrm{C}$ and $25.6^{\circ} \mathrm{C}$ stated in the EREC [Egyptian Code, 2008], which contained the average slightly hot zone values $\left(25.6^{\circ} \mathrm{C}-34.5^{\circ} \mathrm{C}\right)$ and the slightly cold area $\left(22.2^{\circ} \mathrm{C}-17.5^{\circ} \mathrm{C}\right)$.

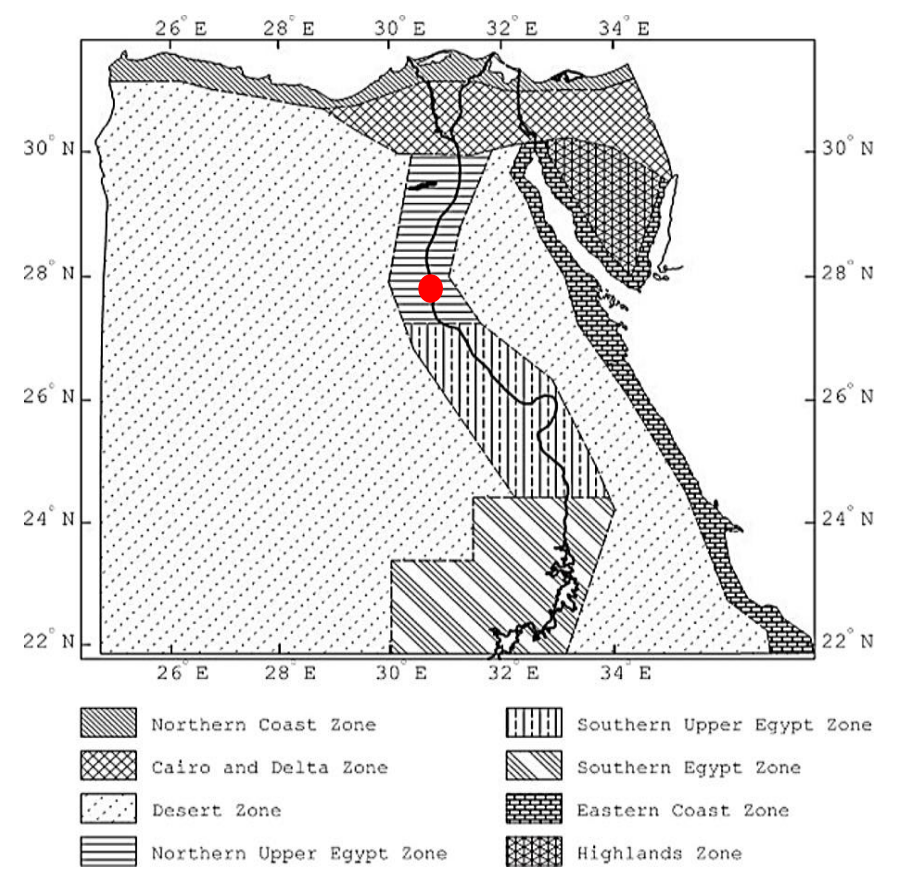

Figure 1. Egypt's eight climatic zones, and the location of Minia city [Fahmy, 2020].

The selected case study is Minia City, which is the capital of Upper Egypt's Minia Governorate. It is situated, at about $245 \mathrm{~km}$ south of Cairo, on the west side of the Nile River. Minia reported being one of North Upper Egypt's climate regions, situated between Longitudes $30^{\circ} 45^{\prime} 1.08^{\prime \prime} \mathrm{E}$ and Latitudes $28^{\circ} 66^{\prime} 35.57$ "N, and has been considered a desert area [Elhadad, 2020]. To analyze the relationship between the environment and the most suitable building comfort design strategies in Minia, the paper adopts the evaluating design strategies based on Mahoney tables using the case study meteorological data [Mcintyre, 1980, Markus et al., 1980]. 
This study seeks to improve accommodation construction assistance processes for building designers in the hot desert region in a more suitable manner for the collaborative application of vernacular tools. The vernacular structures have various strategies that are built for their modification to its general climate. The atmosphere responsive methodologies actualized in vernacular design from many different areas have the potential for being additionally evolved and adjusted in response to current needs. The paper is made up of six items. The first segment describes the subject matter and mentions the objectives. In the second section, the analysis of the literature was defined. The third section is about describing the methodology, which covers the vernacular strategies extracted from the findings of the bioclimatic study to be incorporated and adapted in the architecture of the city, taking into consideration the occupant's thermal comfort aspects and the process established in this study. The results of the city object's bioclimatic analysis are presented in Part Four. Section Fifth deals with outcomes and discussions. The aim is to adjust the housing architecture of the vernacular solutions and offer different recommendations for building design in Minia, Egypt. Finally, the sixth section should consist of a conclusion explaining and synthesizing the collected findings.

\section{LITERATURE REVIEW}

Defining the principles of bioclimatic construction and making them systematically applicable is not easy, since this construction is intimately linked to its environment by nature. By depending on strictly architectural techniques, this style of architecture is vernacular architecture, while taking into account the local context. Analysis and evaluation of vernacular design strategies involve methods that account for the inputs to the thermal equations, the envelope of the building, that allow design strategies effect assessment for the vernacular envelope. These strategies assessed using three tools adapted to the hot climates: the bioclimatic graph [Olgyay et al., 1963], the psychrometric diagram [Szokolay, 2008, Givoni, 1969], and the Mahoney tables [Givoni, 1978]. Many studies during the last decade focus on the climatic surrounded environment using these different strategies, where Mahoney tables are one of these strategies that this study focuses on it.

Aashi et al. 2020, studied in depth the relation between site vernacular architecture, Mahoney tables, Bioclimatic diagram, and Psychometric chart to frame the bioclimatic building design guidelines for a hot and dry environment considering Jaipur City, India situation. They've been framed all-year-round regarding the environment. They have been summarized the strategies that achieve thermal comfort by listing the recommendations. The results related to the classified heads are; open areas must be built for sufficient airflow; however, the living room must be granted due consideration; Window-to-Wall Ratio (WWR): in the Northern and South walls, 20$40 \%$, windows should be supported along wind side. Openings should also be given on the internal walls. Clear sunshine may be left out; Indoor and outdoor walls of high thermal density, thick roofs with a time lag of 8 hours. Outdoor sleeping and seating room offered. Appropriate steps should be taken to guard against rain, and irrigation should be well made.

Mouatassim et al. 2019, interested in the suitable designing of climatic structures as it is a key for smart energy-saving to deal inactively with undesirable out-of-doors circumstances. So, they used three bioclimatic design methods, namely Mahoney tables, Predicted Percentage Dissatisfied (PPD) with the Predicted Mean Vote (PMV) method, and Givoni's Building Bioclimatic Chart (BBCC) approach. The study 
conducted to evaluate the annual thermal comfort and develop appropriate building design strategies for east Moroccan environment buildings based on a 10-year weather file. Their analysis reveals that the Oujda City in Morocco environment offers just 20\% thermal comfort through the normal climatic year, indicating the need for better construction design to increase the degree of thermal comfort. The research findings showed that utilizing appropriate bioclimatic architecture will minimize heating and cooling loads of $45.6 \%$ and $9.5 \%$ of residential buildings, respectively. They concluded that the buildings situated in Oujda City have to be aligned from east to west alliance on Mahoney tables. These buildings have a consolidated design with rigid walls, medium-sized opening, and without built-in spaces. The most effective passive architecture techniques used in Oujda City are robust envelopes for thermal mass construction, solar heating, and natural ventilation at night.

Belkacem et al. 2019, proposed a methodology for building design by combining vaults and mezzanines as vernacular tools to increase buildings' energy efficiency in arid areas, and achieve comfort conditions. So, bioclimatic analysis was carried out in Algeria, Biskra City based on the study of climate characteristics on thermo-isopleths, psychrometric charts, and Mahoney tables. This analysis helps to identify the city's comfort zone, which is the first phase in deciding the techniques to be followed to solve thermal discomfort problems. The results showed a higher thermal load reduction of up to $20.84 \%$ in the energy ratio. The methodology for the building's architectural style in Biskra has been built and applied to achieve these reductions in energy needs. That design takes into consideration both the occupants' comfort aspects and the need for lower energy consumption.

Farheen et al. 2017, sought to investigate techniques unique to contemporary Lucknow buildings in India for thermal comfort and energy efficiency architecture. Bioclimatic Map, Degree Days, Psychometric Graph, and Mahoney's Tables are used for evaluating Lucknow's environment to recommend the criteria for building architecture. At the project design point, these recommendations should include enough knowledge to help architects make efficient use of natural resources, minimize operating costs, and preserve internal thermal comfort through the application of inactive solar technologies. The results indicated that: the design recommendations for the Lucknow City as the orientation of the building should be in the north-south direction, the layout design should be the compact planning around the medium-sized courtyard, along with shades will be the windows opening on the road to the court, where the window-to-wall ratio to be 15-20\%. In Jun., Jul., Aug., and Sept., dense walls and roofs with high temperatures, humidity, and 80 percent of the average annual rainfall are recommended for ventilation. In the cold months of Jan., Feb., Nov., and Dec., the findings also suggest using passive solar heating. Finally, with the right drainage scheme, windows can be covered by projections and roofs.

Santy et al. 2017, investigated the Indonesian climate characteristics using the Olgyay Bioclimatic Map, the Mahoney tables, and the Givoni - Milne Bioclimatic Map as the predesign step for the growth of a residential inactive home design benchmark. Jakarta was the city selected for research, in terms of relative humidity, and temperature. The Olgyay Bioclimatic map shows that the atmosphere needs wind speed to overcome the air pressure and shade to decrease the solar increase. Natural ventilation and shading plans are proposed in the Givoni Bioclimatic Map, while the Mahoney table indorses open places to protect against warm wind, single-packed rooms, and everlasting air drive. Also, the Mahoney table recommended the opening composite size at body tallness for allowing the wind to tackle the strong humidity and 
temperature levels. It suggests heavy walls and roofs, as well as providing safe facilities with heavy rainfall.

Abdollah et al. 2019, Provided bioclimatic architecture techniques to improve the indoor thermal comfort of humans in sticky weather zones based on the Köppen weather category with measuring of temperature. The town of Rasht, Iran, has been specifically investigated as an issue of research. The first step was to analyze the climate data relating to the Mahoney table and the Givoni Bioclimatic Map to identify the suitable bioclimatic architecture techniques to provide the design recommendations. The findings obtained from Mahoney tables showed that; in Nov., Dec., Jan., Feb., Mar., and Apr., the thermal condition is suggested to be maintained with techniques such as expanded east-west alliance, Single-packed air vent, Wide openings (40-80\% of the wall sector), lightweight walls with little temperature roofs, and warm protected ground. However, construction approaches against heavy rain are advised for in any event three months every year. From the test results, Relative Humidity (RH) can be considered as the main factor and climate indicators of these cities. They also suggested using the existing construction techniques as natural and night ventilation.

Maria et al. 2016, analyzed the environmentally friendly architecture approaches implemented in vernacular dwellings for various climatic regions in Cyprus, Greece. They integrated bioclimatic design features with rural settlement designs, building typology, the layout of semi-open and open areas, construction materials and techniques, as well as scale and location of openings in their study. Then the bioclimatic design features are recorded in comparison with the Mahoney table methodology recommendations, to examine to what degree the particularly designed structures have a sustainable architecture pattern, and for a clear approach to local climate and landscape aspects. They illustrated that building architecture, structure design, and building construction should take into account the local environment, topography, and geology. Accordingly, the concepts of architecture are discriminated between the various climatic regions of Cyprus to achieve optimum thermal adaptation. According to their recommendation, the passive approaches are widespread in mountainous areas for optimum solar utilization during winter, as well as defense against frost.

Khalid et al. 2018, studied how to control energy consumption by using the passive concepts of bioclimatic, and solar building. The case study chosen was (new Moroccan home, located in Midelt, and Villa in Marrakech), both were situated in severe climate conditions. Their methodology was based on the building architecture relationship with climate, thermal comfort, and energy performance. The researchers utilized multi-tools to investigate climate situations: Mahoney tables, Szokolay Bioclimatic chart, Olgyay method, and the Givoni Bioclimatic charts. Their results indicated that regarding the layout, the best orientation is North-South with tight yard planning, but, in the case of the size of openings, they suggested medium 25-40\% while, thick walls with thick roofs are recommended. Finally, the external feature suggested that the spaces for outdoor sleeping are required.

Accordingly, to the analysis for the previous literature studies, it is clear that all the researchers agreed with each other in the concept. The findings allowed us deduce that the bioclimatic architecture techniques in different cities and countries could have comparable environments. However, these strategies achieved the increasing of human thermal comfort indoors. 


\section{METHODOLOGY}

This research aims to investigate the interaction of the vernacular strategies on influencing the passive ambient comfort in hot desert zones. To achieve that goal the study followed the following methodology:

The first step is to study the bioclimatic features of the studied city using the climate consultant tool. The purpose is to define the effect of the vernacular approaches arising from this last bioclimatic study on the research target, which incorporates the essential characteristics as cofactors (indicators) that assess the habitat's energy change. The results of the bioclimatic study would be then used as a database for the second step, to formulate the architectural suggestions.

The second step is to examine the vernacular techniques that can be incorporated into the structure of the design. The Mahoney tables are used to indicate the various architectural design approaches that can be implemented by the planners based on the bioclimatic data collected from the climatic consultant tool. That allows for the use of passive technologies to increase the building's thermal efficiency. Then it is up to the designers to choose the solution(s) offering the best alternative in optimizing the metrics, in consideration of the results obtained.

\section{BIOCLIMATIC ANALYSIS}

\subsection{Case Study Analysis}

Climate Consultant 6.0 App is one of the tools that allow us to test the features selected for the case study. It is 'easy-to-use, collaborative programming that displays climatic information in hundreds of ways that are useful to architects and users. At every hour of the year, this system provides temperatures, wind direction, humidity, solar radiation, sundials, and sky cover [Kumar, 2018].

The climate consultant offers the psychrometric chart review that demonstrates the most effective passive architecture techniques. Whereas, the wind wheel given in the program combines the wind direction and velocity with parallel temperature and humidity, which can be shown weekly, regular, or monthly [Murray et al., 2007].

Climate Consultant software [Kumar, 2018] reads the climatic data in the EnergyPlus Weather File (EPW) format, which the Department of Energy offers. Climate Consultancy Program has been studying many factors that impact climate change. Such conditions are discussed in the following.

\subsubsection{Temperature analysis}

Figure 2 shows Minia City's temperature variation over the year, suggesting a dry atmosphere in Minia with a balm summer and a quietly cold winter. Where the typical temperatures vary from high $36.6 \mathrm{oC}$ in July and too low $19.4 \mathrm{oC}$ in January; also, precipitation varies from $52 \%$ to $25 \%$ in January, air velocity falls from 4.2 to 3.4 in August. The study concluded from the analysis of the various climatic parameters throughout the year, that August and July are considered the critical months needed to be considered to achieve thermal comfort.

The hourly average temperature is seen in Fig. 3; Where, on the abscissa and the ordinate, the side temperature is showing the monthly variability. The position, longitude/latitude, elevation, and other information is viewed in the Map's top-right corner, which brings focus to August as a significant month to review. Fig. 4 displays 
the temperature variability and adaptive comfort as the gray part; the bar chart also shows the average temperature above and below the mean value, whereas the yellow portion shows the standard high and low temperature at $23-30^{\circ} \mathrm{C}$ and $22-15^{\circ} \mathrm{C}$ respectively. High-temperature architecture and low-temperature construction fall within the spectrum of respectively $29-39^{\circ} \mathrm{C}$ and $15-1^{\circ} \mathrm{C}$.

\subsubsection{Wind speed analysis}

Variation of wind speeds is caused by air passing from the high to the low level, that moving due to the temperature changes. Where the number of degrees that are measured from the north with the clockwise direction is referred to as the wind direction.

The Climate Data Analysis reveals the month-to-month dedication, where, the additions between lines are measured at 10 degrees. After being enrolled $12 \mathrm{mph}$ maximum, the estimated breeze speed is natural as $1-5 \mathrm{mph}$. The wind rose, defines the prevailing frequency, direction, and intensity of the weather in the city, as seen in Fig. 5. The Red shading displays temperature ranges between $27-38^{\circ} \mathrm{C}$, and deep red shading indicates temperatures over $38^{\circ} \mathrm{C}$. Medium green shading shows a relative humidity of 30-70 percent. The triangle shape in the light orange shading of the pencil nib reflects low wind speed, while the dark orange line indicates high velocity.

\begin{tabular}{|c|c|c|c|c|c|c|c|c|c|c|c|c|c|}
\hline \multicolumn{7}{|l|}{ WEATHER DATA SUMMARY } & \multicolumn{2}{|c|}{$\begin{array}{l}\text { LOCATION: } \\
\text { Latitude/Longitude: } \\
\text { Data Source: }\end{array}$} & \multicolumn{5}{|c|}{$\begin{array}{l}\text { Al Minya, AI Minya, EGY } \\
28.08^{\circ} \text { North, } 30.73^{\circ} \text { East, Time Zone from Greenwich } 2 \\
\text { ETMY } 623870 \text { WMO Station Number, Elevation } 40 \mathrm{~m}\end{array}$} \\
\hline MONTHLY MEANS & JAN & FEB & MAR & APR & MAY & JUN & JUL & AUG & SEP & OCT & Nov & DEC & \\
\hline Global Horiz Radiation (Avg Hourly) & 333 & 407 & 479 & 554 & 584 & 564 & 521 & 497 & 491 & 415 & 354 & 299 & Wh/sa.m \\
\hline Direct Normal Radiation (Avg Hourly) & 320 & 347 & 349 & 422 & 429 & 352 & 287 & 271 & 323 & 295 & 308 & 278 & Wh/sq.m \\
\hline Diffuse Radiation (Avg Hourry) & 162 & 196 & 239 & 256 & 260 & 297 & 304 & 305 & 265 & 231 & 136 & 158 & Wh/sa.m \\
\hline Global Horiz Radiation (Max Hourly) & 907 & 1083 & 1392 & 1383 & 1502 & 1392 & 1243 & 1122 & 1171 & 1043 & 890 & 811 & Wh/sa.m \\
\hline Direct Normal Radiation (Max Hourly) & 1325 & 1434 & 2540 & 2092 & 2445 & 1591 & 1833 & 1002 & 1364 & 1248 & 1619 & 1194 & Wh/sa,m \\
\hline Diffuse Radiation (Max Hourly) & 376 & $4 \$ 2$ & 544 & 652 & 673 & 692 & 683 & 673 & 620 & 535 & 423 & 369 & Wh/sa,m \\
\hline Global Horiz Radiation (Avg Dally Total) & 3478 & $4+32$ & 5693 & 2041 & 7347 & 7757 & 2076 & $64 \% 6$ & 5973 & 4694 & 3758 & 3064 & Wh/sa.m \\
\hline Direct Normal Radiation (Avg Daily Total) & 3343 & 3818 & 4149 & 5372 & 5767 & 4941 & 3908 & 3519 & 3969 & 3342 & 3261 & 2852 & Wh/sa.m \\
\hline Diffuse Radiation (Avg Daily Total) & 1694 & 2154 & 2836 & 3257 & 3503 & 4096 & 4138 & 3963 & 3233 & 2615 & 1976 & 1626 & Wh/sq,m \\
\hline \multicolumn{14}{|l|}{ Global Horiz Illumination (Avg Hourty) } \\
\hline \multicolumn{14}{|l|}{ Direct Normal Illumination (Avg Hourly) } \\
\hline Dry Bulb Temperature (Avg Monthiy) & 12 & 13 & 17 & 22 & 26 & 23 & 28 & 20 & 27 & 24 & 13 & 13 & degrees $C$ \\
\hline Dew Point Temperature (Avg Monthly) & 5 & 5 & 7 & 8 & 9 & 13 & 16 & 16 & 16 & 14 & 10 & 7 & degrees $C$ \\
\hline Relative Humidity (Avg Monthly) & 66 & 59 & 54 & 44 & 37 & 43 & 50 & 48 & 53 & 57 & 63 & 68 & percent \\
\hline Wind Direction (Monthly Mode) & 350 & 0 & 350 & 340 & 10 & 350 & 10 & 340 & 20 & 350 & 340 & 340 & degrees \\
\hline Wind Speed (Avg Monthy) & 1 & 2 & 3 & 3 & 3 & 3 & 3 & 3 & 4 & 2 & 2 & 2 & $\mathrm{~m} / \mathrm{s}$ \\
\hline Ground Temperature (Avo Monthly of 3 Depths) & 16 & 16 & 16 & 17 & 20 & 23 & 26 & 27 & 26 & 24 & 22 & 19 & degrees $\mathrm{C}$ \\
\hline
\end{tabular}

Figure 2. Minia City weather data summary [Climate Consultant tool].

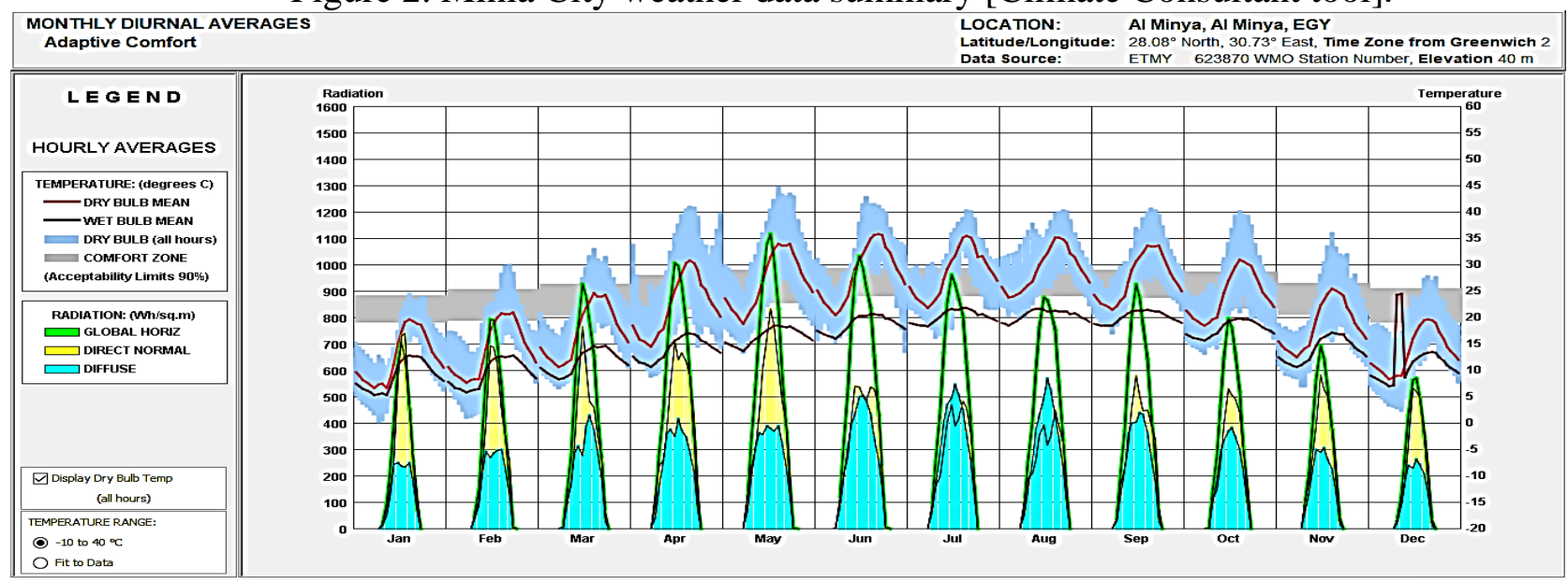

Figure 3. Minia City Hourly Average temperature [Climate Consultant tool]. 


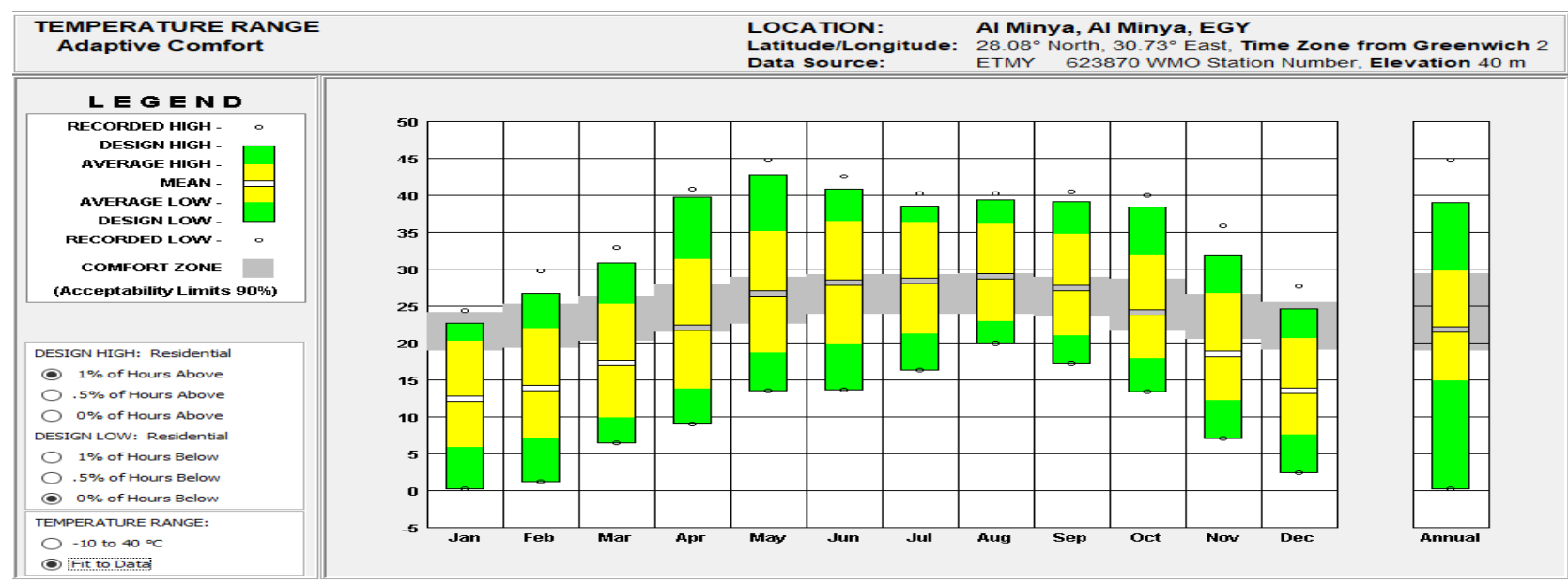

Figure 4. Minia City temperature ranges and the adaptive comfort [Climate Consultant tool].

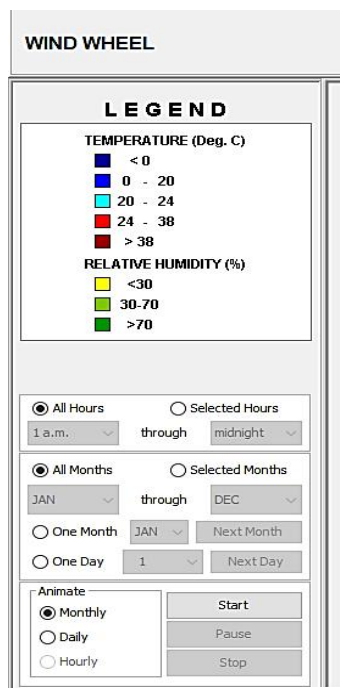

Figure 5. Minia city's wind wheel [Climate Consultant tool].

\subsection{Mahony Tables Analysis for Minia City}

Mahoney Tables are a compilation of reference tables for measuring heat and cold indicators, wet and dry conditions for each month using monthly temperature, relative humidity, and precipitation. The synthesis of these metrics can be translated into easy architecture recommendations: reduction/increase of sun exposure, the arrangement of spaces by activity and functionality, and many other recommendations [Sealey, 1979].

Such bioclimatic analysis and thermal indicators allow the measurement of thermal comfort to be on a global scale, hence the integration of knowledge will gain general feedback for the initial stages in the design process. Even if these indicators are gained from datasets or measurements, these shouldn't be converted directly into energy-efficient designs [Sellem et al., 2007]. However, this analysis provides a framework for designers 'How to Design' to help them to understand the techniques like these indicators [Kemajou, 2011]. Also, the design process in some climatic regions (hot, arid, and desert) needs assistance tools to achieve thermal comfort or to decrease energy consumption which is from the concepts of green construction [Susanne et al., 2014]. 
The Mahoney tables analyze the meteorological parameters such as the monthly lowest temperature, average monthly high temperature, mean monthly range, relative humidity, and precipitation. These parameters are gotten from the analysis in Sec 4.1 as input data for the Mahoney tables to get a suitable strategy for designing in Minia City to complete the Minia climate analysis. Where Table 1 Indicates the humidity group as mentioned in Mahoney tables to classify the mean relative humidity ranges between groups 2, and 3 in Minia City.

The first step to get the strategies for the design in Minia is to analyze the climatic data, so, Table 2 summarizes the climatic data for the location. However, we can calculate the Annual Mean Temperature (AMT) using Eq. (1). Table 3 gives the monthly mean max., min., a range for the relative humidity in Minia City. However, we can observe that the highest monthly mean humidity is 67 in December and the lowest monthly mean is 36 in May; Also, we can calculate the Annual Mean Range of humidity (AMR) using Eq. (2). Also, the annual average rainfall for Minia City is 0.5 mm.

$$
\begin{array}{ll}
A M T=(\text { Highest }+ \text { Lowest }) / 2=21.3^{\circ} \mathrm{C} & \text { Eq. (1) } \\
A M R=\text { Highest }- \text { Lowest }=31 \% & \text { Eq. (2) }
\end{array}
$$

Table 1. The Classification of Mean Relative Humidity Regarding the Humidity Group.

\begin{tabular}{cc}
\hline Mean Relative Humidity & Humidity Group (HG) \\
\hline Below 30\% & 1 \\
$30-50 \%$ & 2 \\
$51-70 \%$ & 3 \\
Above $70 \%$ & 4 \\
\hline
\end{tabular}

Table 2. Minia Climatic Data Analysis.

\begin{tabular}{lccccccccccccc}
\hline \multicolumn{1}{c}{ Month } & $\mathbf{J}$ & $\mathbf{F}$ & $\mathbf{M}$ & $\mathbf{A}$ & $\mathbf{M}$ & $\mathbf{J}$ & $\mathbf{J}$ & $\mathbf{A}$ & $\mathbf{S}$ & $\mathbf{O}$ & $\mathbf{N}$ & D & AMT \\
\hline Monthly mean max $\left({ }^{\circ} \mathrm{C}\right)$ & 21 & 22 & 26 & 31 & 35 & 35 & 37 & 36 & 33 & 32 & 27 & 22.5 & 21.3 \\
Day comfort upper $\left({ }^{\circ} \mathrm{C}\right)$ & 29 & 29 & 29 & 31 & 31 & 31 & 29 & 29 & 29 & 29 & 29 & 29 & \\
Day comfort lower $\left({ }^{\circ} \mathrm{C}\right)$ & 23 & 23 & 23 & 25 & 25 & 25 & 23 & 23 & 23 & 23 & 23 & 23 & \\
Monthly mean min $\left({ }^{\circ} \mathrm{C}\right)$ & 4 & 5 & 8 & 12 & 16 & 18 & 20 & 20 & 18 & 15 & 11 & 7.5 & \\
Night comfort upper $\left({ }^{\circ} \mathrm{C}\right)$ & 23 & 23 & 23 & 24 & 24 & 24 & 23 & 23 & 23 & 23 & 23 & 23 & \\
Night comfort lower $\left({ }^{\circ} \mathrm{C}\right)$ & 17 & 17 & 17 & 17 & 17 & 17 & 17 & 17 & 17 & 17 & 17 & 17 & \\
Thermal stress day & $\mathrm{C}$ & $\mathrm{C}$ & $\mathrm{N}$ & $\mathrm{N}$ & $\mathrm{H}$ & $\mathrm{H}$ & $\mathrm{H}$ & $\mathrm{H}$ & $\mathrm{H}$ & $\mathrm{H}$ & $\mathrm{N}$ & $\mathrm{C}$ & \\
Thermal stress night & $\mathrm{C}$ & $\mathrm{C}$ & $\mathrm{C}$ & $\mathrm{C}$ & $\mathrm{C}$ & $\mathrm{N}$ & $\mathrm{N}$ & $\mathrm{N}$ & $\mathrm{N}$ & $\mathrm{C}$ & $\mathrm{C}$ & $\mathrm{C}$ & \\
\hline
\end{tabular}

* Where, C: below comfort limit; $\mathrm{N}$ : within comfort limit; $\mathrm{H}$ : above comfort limit.

Table 3. Monthly Relative Humidity Means Max, Min., Range in Minia City.

\begin{tabular}{lccccccccccccc}
\hline \multicolumn{1}{c}{ Month } & J & F & M & A & M & J & J & A & S & O & N & D & AMR \\
\hline Monthly mean max. $\left({ }^{\%}\right)$ & 60.5 & 54 & 54 & 47.5 & 41 & 47 & 47 & 54 & 60 & 60 & 59 & $67 *$ & 31 \\
Monthly mean min. ${ }^{\%}$ ) & 56 & 51 & 49 & 41 & $36 \#$ & 41 & 45 & 50 & 56 & 54 & 59 & 61 & \\
Monthly mean range $(\%)$ & 58 & 52.5 & 51.5 & 44 & 38.5 & 44 & 46 & 52 & 58 & 57 & 59 & 64 & \\
\hline
\end{tabular}




\begin{tabular}{|c|c|c|c|c|c|c|c|c|c|c|c|c|}
\hline RH & 17 & 17 & 18 & 19 & 19 & 17 & 17 & 16 & 15 & 17 & 16 & 15 \\
\hline $\mathrm{HG}$ & 3 & 3 & 3 & 2 & 2 & 2 & 2 & 3 & 3 & 3 & 3 & 3 \\
\hline
\end{tabular}

* Highest monthly mean; \#Lowest monthly mean; HG: Humidity Group; RH: Relative Humidity.

\subsubsection{The thermal comfort limits in Mahoney tables}

The Mahoney tables evaluate the citizen's climate adaptability in various climatic regions to assess thermal comfort limits and split the comfort zones into three temperatures. Ranges of the AMT level are: $\geq 20^{\circ} \mathrm{C}, 15 \sim 20^{\circ} \mathrm{C}$ and $<15^{\circ} \mathrm{C}$. Also, the tables take into consideration people's variations in day and night clothing patterns, behaviors and reduce the gap between day and night thermal comforts, as shown in Table 4.

\subsubsection{The analysis of comfort limits in every month}

The monthly mean maximum and minimum of the site concerned are correlated with the comfort limits during daytime and nighttime for each particular month, based on the annual average scopes specified in Table 4 (maxima with a limit of day comfort and minimal with a limit of night comfort). The classifications of humidity and comfort levels are correlated to humidity and dry indicators for each month, as indicated in Table 5.

Table 6 calculates the total indicators based on the data that indicated in Table 5; however, we can direct the indicators for each month using the HG, thermal stress, and monthly mean temperature range that given in Table 2. Where these indicators From $\mathrm{H} 1$ to A3 indicated in the previous tables can be defined as the following [Xia, 2013]:

H1 means that there is substantial air circulation. It happens when high temperatures "day thermal stress $=\mathrm{H}$ " are merged with high humidity equal to 4 , or when high temperatures are combined with humidity ( $\mathrm{HG}=2$ or 3 ) with minimal diurnal variance $\left(<10^{\circ} \mathrm{C}\right)$. $\mathrm{H} 2$ shows the desirability of air motion. It happens when the temperature is coupled with high humidity $(\mathrm{HG}=4)$ beyond the comfort range "day thermal stress $=\mathrm{N}$ ". H3, indicates safeguards are required in contradiction of rain dissemination. Difficulties may occur with only small precipitation, but as rainfall reaches $200 \mathrm{~mm}$ per month, it would be unavoidable. A1 needs thermal energy. Happens where a broad diurnal spectrum correlates with high to low humidity ( $\mathrm{HG}=1$, 2 , or 3$)\left(10^{\circ} \mathrm{C}\right.$ or more). A2 indicates whose outdoor living area is ideal. If the nightly temperature is elevated "night thermal stress $=\mathrm{H}$ ", and $(\mathrm{HG}=1$ or 2$)$, then it is necessary. Even when nights are cold outdoors yet hot indoors related to massive thermal storage "day $=\mathrm{H}$, night $=\mathrm{N}, \mathrm{HG}=1$ or 2 ", and when the day temperature is overhead $10^{\circ} \mathrm{C}$, it might be required. A3 refers to the issue of winter or cold season, which arises throughout the day while there is thermal stress $=\mathrm{C}$. That total of the monthly indicator can help to recommend design strategies, which will be discussed in the following section.

Table 4. The Comfort limits.

\begin{tabular}{lccccccc}
\hline $\begin{array}{l}\text { Comfort } \\
\text { Range }\end{array}$ & HG & \multicolumn{2}{c}{ AMT over 20 ${ }^{\circ} \mathbf{C}$} & \multicolumn{2}{c}{ AMT 15-20 ${ }^{\circ} \mathbf{C}$} & \multicolumn{2}{c}{$\begin{array}{c}\text { AMT under } \\
\mathbf{1 5}^{\circ} \mathbf{C}\end{array}$} \\
Average RH & & Day & Night & Day & Night & Day & Night \\
\hline Below 30\% & 1 & $26-34$ & $27-25$ & $23-32$ & $14-23$ & $21-30$ & $12-21$ \\
$30-50 \%$ & 2 & $25-31$ & $17-24$ & $22-30$ & $14-22$ & $20-27$ & $12-20$ \\
$51-70 \%$ & 3 & $23-29$ & $17-23$ & $21-28$ & $14-21$ & $19-26$ & $12-19$ \\
Above 70\% & 4 & $22-27$ & $17-21$ & $20-25$ & $14-20$ & $18-24$ & $12-18$ \\
\hline
\end{tabular}


Table 5. Marking of Humid and Arid Indicators.

\begin{tabular}{|c|c|c|c|c|c|}
\hline \multirow[t]{2}{*}{ indicator } & \multicolumn{2}{|c|}{ Thermal stress } & \multirow{2}{*}{$\begin{array}{l}\text { Monthly } \\
\text { Rainfall }\end{array}$} & \multirow[t]{2}{*}{ HG } & \multirow{2}{*}{$\begin{array}{c}\text { Monthly } \\
\text { Mean Tem. } \\
\text { Range } \\
\end{array}$} \\
\hline & Day & Night & & & \\
\hline \multirow{2}{*}{ H1 (Air movement essential) } & $\mathrm{H}$ & & & 4 & \\
\hline & $\mathrm{H}$ & & & 2,3 & $<10^{\circ} \mathrm{C}$ \\
\hline H2 (Air movement desirable) & $\mathrm{N}$ & & & 4 & \\
\hline H3 (Rain Protection) & & & $>200 \mathrm{~mm} / \mathrm{month}$ & & \\
\hline A1 (Thermal storage) & & & & $1,2,3$ & $>10^{\circ} \mathrm{C}$ \\
\hline \multirow[t]{2}{*}{ (Outdoor sleeping) } & & $\mathrm{H}$ & & 1,2 & \\
\hline & $\mathrm{H}$ & $\mathrm{N}$ & & 1,2 & $>10^{\circ} \mathrm{C}$ \\
\hline A3 (Cold season problem) & $\mathrm{C}$ & & & & \\
\hline
\end{tabular}

Table 6. The Indicators for Each Month.

\begin{tabular}{|c|c|c|c|c|c|c|c|c|c|c|c|c|c|c|c|}
\hline \multicolumn{3}{|c|}{ Month / Indicator } & $\mathbf{J}$ & $\mathbf{F}$ & M & $\mathbf{A}$ & $\mathbf{M}$ & $\mathbf{J}$ & $\mathbf{J}$ & A & $\underline{\mathbf{S}}$ & O & $\mathbf{N}$ & D & Total \\
\hline \multirow{3}{*}{ 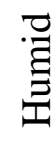 } & H1 & Air movement essential & & & & & & & & & & & & & 0 \\
\hline & $\mathrm{H} 2$ & Air movement desirable & & & & & & & & & & & & & 0 \\
\hline & H3 & Rain Protection & & & & & & & & & & & & & 0 \\
\hline \multirow{3}{*}{ 龸 } & A1 & Thermal storage & 0 & 0 & 0 & 0 & 0 & 0 & 0 & 0 & ( & 0 & & 0 & 12 \\
\hline & $\mathrm{A} 2$ & Outdoor sleeping & & & & & & 0 & 0 & & & & & & 2 \\
\hline & A3 & Cold season problem & 0 & 0 & & & & & & & & & & 0 & 3 \\
\hline
\end{tabular}

Table 7. Urban and Design Recommendations for Minia City.

\begin{tabular}{|c|c|c|c|c|c|c|c|c|}
\hline \multirow{4}{*}{ Recommendations } & & & \multicolumn{6}{|c|}{ The total indicators from Table 6.} \\
\hline & & & \multicolumn{3}{|c|}{ Arid } & \multicolumn{3}{|c|}{ Humid } \\
\hline & & & A3 & $\mathrm{A} 2$ & A1 & $\mathrm{H} 3$ & $\mathrm{H} 2$ & $\mathrm{H} 1$ \\
\hline & & & 3 & 2 & 12 & 0 & 0 & 0 \\
\hline \multicolumn{9}{|l|}{ Layout } \\
\hline \multirow{2}{*}{$\begin{array}{l}\text { Building oriented on the east to the west axis to reduce exposure to } \\
\text { the sun }\end{array}$} & \multirow[t]{2}{*}{1} & & & & $0-10$ & & & \\
\hline & & & $5-12$ & & \multirow[t]{2}{*}{11,12} & & & \\
\hline Compact courtyard planning & 2 & $\star$ & $0-4$ & & & & & \\
\hline \multicolumn{9}{|l|}{ Spacing } \\
\hline Open spacing for breeze penetration & 3 & & & & & & & 11,12 \\
\hline As 3 , but protect from cold/hot wind & 4 & & & & & & & $2-10$ \\
\hline Compact planning & 5 & $\star$ & & & & & & 0,1 \\
\hline \multicolumn{9}{|l|}{ Air movement } \\
\hline \multirow[t]{2}{*}{ Rooms single banked. Permanent provision for air movement } & \multirow[t]{2}{*}{6} & & & & & & & $1-12$ \\
\hline & & & & & $0-5$ & & & \multirow[t]{2}{*}{1,2} \\
\hline \multirow[t]{2}{*}{ Double banked rooms with temporary provision for air movement } & \multirow[t]{2}{*}{7} & & & & $6-12$ & & & \\
\hline & & & & & & & 2,12 & \\
\hline No air movement required & 8 & $\star$ & & & & & 0,1 & \\
\hline \multicolumn{9}{|l|}{ Openings } \\
\hline Large openings, $40-80 \%$ of $\mathrm{N}$ and $\mathrm{S}$ & 9 & & 0 & & 0,1 & & & \\
\hline Very small openings,10-20\% Any other conditions & 10 & $\star$ & 0,1 & & 11,12 & & & \\
\hline Medium openings, $20-40 \%$ & 11 & & & & & \multicolumn{3}{|c|}{ Any other conditions } \\
\hline \multicolumn{9}{|l|}{ Walls } \\
\hline Light walls; short time lag & 12 & & & & $0-2$ & & & \\
\hline Heavy external and internal walls & 13 & $\star$ & & & $3-12$ & & & \\
\hline \multicolumn{9}{|l|}{ Roofs } \\
\hline Lightly insulated roofs & 14 & & & & $0-5$ & & & \\
\hline Heavy roofs; over 8 hours' time lag & 15 & $\star$ & & & $6-12$ & & & \\
\hline \multicolumn{9}{|l|}{ Outdoor sleeping } \\
\hline Space for outdoor sleeping required & 16 & $\star$ & & $2-12$ & & & & \\
\hline \multicolumn{9}{|l|}{ Rain protection } \\
\hline Protection from heavy rain needed & 17 & -- & & & & $3-12$ & & \\
\hline
\end{tabular}


Table 8. Architectural Recommendations for Minia City.

\begin{tabular}{|c|c|c|c|c|c|c|c|c|}
\hline Hole size relative to the wall & & & & & & & & \\
\hline Large openings, $40 \%-80 \%$ of wall area & 1 & & 0 & & \multirow[t]{2}{*}{0,1} & & & \\
\hline \multirow[t]{2}{*}{ Medium openings, $25 \%-40 \%$ of wall area } & \multirow[t]{2}{*}{2} & & $1-12$ & & & & & \\
\hline & & & & & $2-5$ & & & \\
\hline small openings, $15 \%-25 \%$ of wall area & 3 & & & & $6-10$ & & & \\
\hline Very small openings, $10 \%-20 \%$ of wall area & 4 & $\star$ & $0-3$ & & \multirow{2}{*}{$\begin{array}{l}11,1 \\
2\end{array}$} & & & \\
\hline Medium openings, $25 \%-40 \%$ of wall area & 5 & & 4-12 & & & & & \\
\hline \multicolumn{9}{|l|}{ Position of the Opening } \\
\hline \multirow[t]{2}{*}{ In the direction of wind gusts } & \multirow[t]{2}{*}{6} & & & & & & & 3-12 \\
\hline & & & & & $0-5$ & & & \multirow[t]{2}{*}{1,2} \\
\hline \multirow[t]{2}{*}{ In N and south walls at body height and also in internal walls } & \multirow[t]{2}{*}{7} & \multirow[t]{2}{*}{$\star$} & & & $6-12$ & & & \\
\hline & & & & & & & 2,12 & 0 \\
\hline \multicolumn{9}{|l|}{ Protection of Openings } \\
\hline Protect from rain and direct sunlight & 8 & -- & $0-2$ & & & & & \\
\hline Protect from rain & 9 & -- & 0 & & & $2-12$ & & \\
\hline \multicolumn{9}{|l|}{ Walls and Grounds } \\
\hline Light and low heat capacity walls & 10 & & & & $0-2$ & & & \\
\hline Heavy walls, over an 8-h time lag & 11 & $\star$ & & & 3-12 & & & \\
\hline \multicolumn{9}{|l|}{ Roofs } \\
\hline Light reflected, and hollow roofs & 12 & & & & $0-2$ & & & \multirow[t]{2}{*}{$10-12$} \\
\hline \multirow[t]{2}{*}{ Lightly insulated roofs } & \multirow[t]{2}{*}{13} & & & & 3-12 & & & \\
\hline & & & & & $0-5$ & & & \multirow[t]{2}{*}{0,9} \\
\hline Heavy roofs; over an 8-h time lag & 14 & $\star$ & & & 6-12 & & & \\
\hline \multicolumn{9}{|l|}{ External features } \\
\hline Space for outdoor sleeping required & 15 & $\star$ & & $1-12$ & & & & \\
\hline Protection from heavy rain needed & 16 & & & & & $1-12$ & & \\
\hline
\end{tabular}

$\star$ In the table is an indication of the appropriate strategies for a building design for Minia city)

\section{DESIGN RECOMMENDATION FOR MINIA CITY}

The Mahoney tables established a partnership between temperature indices and building design. In Mahoney's Table 7, and Table 8 where the urban and design approvals are analyzed based on the indicators related to the case study. In tables 7, and 8 the association between Minia's environment observations and guidelines implementation approaches is tabulated according to the total indications resulted from Table 6 . Where stars $(\star)$ denote the comparison between the total indicators, and its numbering that is given in tables 7 , and 8 (as an example, $A 3=3$ that comes from table 6 means the total indicators for each month equal 3, so we put a star in between 0-4 in the layout recommendation in table 7). Finally, the environment research guidelines (urban, design, and architectural) for constructing Minia buildings are summarized in Table 9.

The summary in Table 9 indicates the design recommendation deduced from Mahoney tables 7, 8 analyzation, where the layout is recommended to be a compact yard or single-banked places around the mid-size yard; additionally, vernacular architecture often educates the same result. Due to the small surface area to volume ratio, lightweight design, and the usage of shared partitions, heat loss through the interiors may be minimized. It also offers a compact planning space that can be used for seating in summer at night and in winter in the daytime. Moreover, the WWR ratio suggested from the table of Mahoney is 15-20 percent to mitigate heat increase inside the building with sufficient sunshine.

Also, the openings should be in both the North and South directions, where the shading of windows that direct solar radiation and hence the power production should be constructed according to the way the windows are positioned in the house. Results also recommend ventilation in Jun., Jul., Aug., and Sept. months that have a high 
temperature, and humidity. Dense external walls and roofs are recommended and also for inactive solar heating in Jan., Feb., Nov., and Dec.

According to this study, there are many impacts on the architectonic structure that conceivable to verify that beyond the multiple climatic factors. For instance, despite the fact that air development isn't needed for the absence of humidity that tends to be needed for legitimate ventilation. Contemplating the outcomes introduced in this study, it may be expressed that, the climate-responsive inactive procedures utilized in vernacular engineering to moderate the impacts of the environment, because of their straightforwardness and logic, which can possibly be improved and adjusted to contemporary development.

Table 9. Bioclimatic Analysis for Building Design in Minia City.

\begin{tabular}{ll}
\hline \multicolumn{1}{c}{ Element } & \multicolumn{1}{c}{ Recommendations } \\
\hline Layout & Compact courtyard planning \\
Spacing & Compact planning \\
Air Movement & No air movement required \\
Openings & Very small openings, 10-20\% Any other conditions \\
Walls & Heavy external and internal walls \\
Roofs & Heavy roofs; over 8 hours' time lag \\
Outdoor sleeping & Space for outdoor sleeping required \\
Hole size relative to the wall & Very small openings, 10\%-20\% of wall area \\
Position of the Opening & In N and south walls at body height and also in internal \\
& walls \\
Walls and Grounds & Heavy walls, over an 8-h time lag \\
Roofs & Heavy roofs; over an 8-h time lag \\
External features & Space for outdoor sleeping required \\
\hline
\end{tabular}

\section{CONCLUSIONS}

The construction of a building related to the environment has many advantages, firstly, makes the usage of renewable resources, secondly decrease the need for operating energy, which helps to increases the thermal comfort that leads to the satisfaction of users. However, the recommendations for bioclimatic planning is drawn up based on the findings of the environment research and the review of vernacular Minia City architecture.

The Mahoney tables are primarily aimed at the tropical climate, therefore the process used to assess the Minia climate can more accurately reflect the environmental conditions in the summer. Minia inhabitants are more accommodating to the hot and cold weather while the purpose of the building is to provide citizens a relaxed indoor climate. Therefore, it is necessary to beware of the passive heating technique as natural ventilation used in the construction of energy-efficient buildings.

The guidelines for the bioclimatic architecture of buildings will help designers with creative and practical design approaches to preserve the comfort of the interior. That guide has given through a comprehensive analysis for the climatic data; then, the different urban, design and architectural recommendations are concluded each as an indicator to deal with the buildings.

Also, these recommendations would include sufficient knowledge at the project design level to enable architects to make efficient usage of natural aids, minimize operating energy and preserve thermal comfort indoors through the help of passive solar strategies. That recommendations play a vital role in achieving thermal comfort in the 
structure located inside the Minia climate zone. However, thermal comfort is one of the concepts of green building. The approach used in this paper will allow students of architecture to know how to integrate their design into the surrounding environment.

\section{REFERENCES}

Aashi K., et al. (2020). Framing Bioclimatic Building Design Guidelines for Hot and Dry Climate: Case of Jaipur City. International Journal for Research in Applied Science \& Engineering Technology (IJRASET), ISSN: 2321-9653; IC Value: 45.98; SJ Impact Factor: 7.429, Volume 8, Issue 4.

Abdollah B., et al. (2019). Bioclimatic design strategies: A guideline to enhance human thermal comfort in Cfa climate zones. Journal of Building Engineering 25, 100758.

Mahmoud A. (2011). An analysis of bioclimatic zones and implications for design of outdoor built environments in Egypt. Build Environ, 46 (3) 605-620.

Ali S., and Hamid A. (1998). Thermal comfort and the development of bioclimatic concept in building design. Renewable and Sustainable Energy Reviews, vol.2, no.1-2, pp.3-24.

Ashwani K., et al. (2018). Climate Consultant: A Software for Designing Energy Efficient Building. International Journal for Research in Applied Science \& Engineering Technology (IJRASET), ISSN: 2321-9653; IC Value: 45.98; SJ Impact Factor: 6.887, Volume 6, Issue 9.

Baruch G. (1992). Comfort, climate analysis and building design guidelines. Energy and Buildings, vol.18, no.1, pp.11-23.

Belkacem B., and Daniel F. (2019). Passive ambient comfort and the interaction of vernacular strategies and devices in arid zone habitat design: case of Biskra, Algeria. Advances in Building Energy Research, DOI: 10.1080/17512549.2019.1607775.

Bo X. (2013). Thermal comfort and the Mahoney tables in Shanghai building bioclimatic design", Advances in Information Sciences and Service Sciences (AISS), Volume 5, Issue 9, May, DOI: 10.4156/AISS.

Givoni B. (1998). Climate considerations in building and urban design, John Wiley \& Sons, New York.

Charai M., et al. (2019). Bioclimatic Building Design Analysis. Case Study: Oujda, Morocco. 7th IEEE International Renewable and Sustainable Energy Conference (IRSEC), pp. 1-6.

McIntyre, D.A. (1980). Indoor Climate. Applied Science Publishers LTD, London.

Ministry of Housing, Cairo, Egypt. (2008). Housing, and Building National Research Centre, Report, Egyptian Code for Improving the Efficiency of Energy Use in Buildings, Part 1: Residential Buildings (306/1). ECP 305.

Farheen B., and Mohammad T. (2017). Bioclimatic Building Design Guidelines for Lucknow City: Use of Various Climate Analysis Methods. International Journal for Research in Applied Science \& Engineering Technology (IJRASET), ISSN: 2321-9653; IC Value: 45.98; SJ Impact Factor:6.887, Volume 5, Issue 11.

Givoni B. (1969). Man, climate, and architecture. London: Elsevier Publishing Company Limited. 
Givoni, B. (1978). L’homme, l'architecture et le climat. Paris : Éditions du Moniteur.

Megahed T., and Radwan A., (2020). Performance investigation of zero-building integrated photovoltaic roof system : A case study in Egypt. Alexandria Engineering Journal, 59(6), pp.5053-5067.

Elhadad S., et al. (2020). Model Simplification on Energy and Comfort Simulation Analysis for Residential Building Design in Hot and Arid Climate. Energies, 13(8), p.1876.

Kemajou A., and Mba L. (2011). Matériaux de construction et confort thermique en zone chaude Application au cas des régions climatiques camerounaises. 'ENSET'. Revue des Energies Renouvelables, 14(2), 239-248.

Khalid E., et al. (2018). Energy Efficient Houses Meeting Both Bioclimatic Architecture Principles and Moroccan Thermal Regulation, IEEE.

Humphreys M. (1996). Thermal comfort temperatures world-wide - the current position, Renew Energy 8 (1-4) 139-144.

Humphreys M., et al. (2013). Updating the adaptive relation between climate and comfort indoors; new insights and an extended database, Build Environ 63, 40-55.

Milne M., et al. (2007). Climate consultant 3.0: A tool for visualizing building energy implications of climates. In proceedings of the Solar Conference, American Solar Energy Society; American Institute of Architects, vol. 1, p. 466.

Fahmy M., et al. (2020). Influence of urban canopy green coverage and future climate change scenarios on energy consumption of new suburban residential developments using coupled simulation techniques: A case study in Alexandria, Egypt, Energy Reports, https://doi.org/10.1016/j.egyr.2019.09.042.

Sellem H., and Alkama D. (2009). Le confort thermique entre perception et évaluation par les techniques d'analyse bioclimatique- Cas des lieux de travail dans les milieux arides à climat chaud et sec. Revue des Energies Renouvelables, 12(3), 471-488.

Olgyay V., and Olgyay A. (1963). Design with Climate: Bioclimatic approach to architectural regionalism. Some chapters based on cooperative research with Aladar Olgyay. Princeton, NJ: Princeton University Press.

Philokyprou M., et al. (2016). Environmentally responsive design in Eastern Mediterranean. The case of vernacular architecture in the coastal, lowland, and mountainous regions of Cyprus, Building and Environment, DOI: 10.1016/j.buildenv.2016.10.010.

Santy, et al. (2017). Bioclimatic Analysis in Pre-Design Stage of Passive House in Indonesia, Buildings, 7, 24; DOI:10.3390/buildings7010024.

Sealey A. (1979). Introduction to Building Climatology-Chapter 10-The Mahoney Tables.pdf. An Introduction to Building Climatology; Commonwealth Association of Architects: London, UK.

Susanne B., et al. (2014). Climate responsive building design strategies of vernacular architecture in Nepal. Energy and Buildings, 81, 227-242. 
Szokolay S. (2008). Introduction to architectural science: The basis of sustainable design. London: Architectural Press (1st and 2nd ed.).

Markus T., and Edwin N. (1980). Building, Climate and Energy, Pitman Publishing Ltd, USA. 